\title{
Species Relationships in Hordeum: Cytology and RAPD Analyses
}

\author{
Masoud Sheidai ${ }^{1, *}$, Fatemeh Jaffari ${ }^{1}$, Maryam Keshavarzi ${ }^{2}$ and \\ Zahra Noormohammadi ${ }^{3}$ \\ ${ }^{1}$ Shahid Beheshti University, GC, Faculty of Biological Sciences, Tehran, Iran \\ ${ }^{2}$ Biology Department, Al-Zahra University, Tehran, Iran \\ ${ }^{3}$ Biology Department, School of Basic sciences, Science and Research Branch, \\ Islamic Azad University (SRBIAU), Poonak, Tehran, Iran
}

Received July 9, 2009; accepted August 25, 2009

\begin{abstract}
Summary Cytological and molecular studies were performed on 10 Hordeum species of Iran. The species studied showed the occurrence of $2 n=2 x=14,2 n=4 x=28$ and $2 n=6 x=42$. They formed mainly bivalents in metaphase with normal chromosomes segregation during anaphase and telophase stages, except in few cases of laggard chromosomes formation and chromosome stickiness observed in H. bulbosum. H. bulbosum and H. leporinum showed 0-2 B-chromosomes which were smaller than A-chromosomes and did not pair with them out of 20 RAPD primers used 11 primers produced 18 reproducible polymorphic bands. Specific bands were observed in some of the species or populations while, some bands occurred in all the species except one showing the species genetic differences. Clustering of the species based on cytological and RAPD data partly produced similar results, separating $H$. vulgare and $H$. spontaneum from each other. The species of $H$. marinum, $H$. glaucum and $H$. leporinum from the sect. Hordeastrum were grouped together, while H. violaceum H. bogdanii and H. brevisubulatum, from the sect. Stenostachys were placed in different clusters separated from each other. $H$. bulbosum and $H$. vulgare showed a close relationship, while $H$. spontaneum, $H$. distichon and $H$. vulgare were placed close to each other supporting their taxonomic position in Flora Iranica.
\end{abstract}

Key words Cytology, Hordeum, Iran, RAPD, Taxonomy.

The genus Hordeum L. (Pooideae) is considered among difficult plant groups from the standpoints of evolution and taxonomy, containing about 30 species growing in the North temperate and South America as well as in South-West and central Asia. They are annual or perennial taxa usually growing in open weedy or sandy places but mostly in dry soils (Bothmer et al. 1991, Shewry 1992, Watson and Dallwitz 1992), including weedy species like H. jubatum, H. leporinum, H. marinum, $H$. murinum and important grain crop species like Barley (H. vulgare). The Hordeum base chromosome number is $x=7$, and it contains about 40 diploid $(2 n=2 x=14)$, tetraploid $(2 n=4 x=28)$ and hexaploid $(2 n=6 x=42)$ species (Bothmer et al. 1995). The chromosomes are large, with haploid nuclear DNA content 5.4-5.6 pg and mean diploid 2c DNA value of $11 \mathrm{pg}$. The species hybridize with species of other genera like Elytrigia ( $\times$ Elytrordeum Hylander, $\times$ Elyhordeum Zizan \& Petrowa), Agropyron ( $\times$ Agrohordeum A. Camus), Secale $(\times$ Hordale Ciferri and Giacom.), Sitanion ( $\times$ Sitordeum Bowden), Triticum ( $\times$ Tritordeum Aschers. and Graebn.) (Watson and Dallwitz 1992).

Blattner (2004) suggested that the genus Hordeum originated about 12 MYA in western Eurasia then expanded its distribution to Europe, central Asia, North America, South America, and South Africa. A morphological study made by Seberg and Frederiksen (2001) suggested monophyly of the genus, which was supported by morphological and molecular phylogenetic studies of

\footnotetext{
*Corresponding author, e-mail: msheidai@sbu.ac.ir, msheidai@yahoo.com
} 
the latter researchers (Petersen and Seberg 1997, Blattner 2004). The classification of the genus Hordeum was initially based on morphological traits, later on cytogenetic traits, and the ability of species to hybridize and produce fertile progeny in crosses was used in systematics of the genus (Bothmer and Jacobsen 1985). Controversy exists about taxonomic treatment of the genus Hordeum; for example Åberg (1940) divided the genus into 4 sections of Stenostachys, Bulbohordeum, Campestria and Cerealia (the first 2 sections are perennial and the other 2 are annual) while Nevski (1941) divided the genus into 6 sections of Critesion, Stenostachys, Anisolepis, Hordeastrum, Bulbohordeum and Crithe. Later on Bothmer and Jacobsen (1985), by considering the growth pattern, phytogeography, ecology, cytology and cross compatibility of the Hordeum species divided the species in 4 sections of Hordeum, Stenostachys, Anisolepis and Critesion. Difficulties exist in the species morphological characters due to the presence of complex patterns of shared characters across taxa (Bachmann 1998). These problems have led to controversies about taxonomic status of several taxa within the genus. For instance, some researchers consider $H$. geniculatum All., as a separate species but other authors assign it to $H$. marinum Huds. sensu lato. Likewise, taxonomic relationships between H. murinum and H. glaucum are not completely established (Kochieva et al. 2001). The other point is that Hordeum species hybridize with each other further complicating reconstruction of the evolutionary history of the genus (Bothmer and Jacobsen 1985).

Extensive cytological studies have been carried out in the genus Hordeum mainly concerned with chromosome number and polyploidy level (Bothmer 1979, Bothmer et al. 1986a, b, 1987, Zhang et al. 1990, Jahan et al. 1992, Bothmer et al. 1995, Bao-Rong 1997, Sheidai et al. 2008). The study of the meiotic behaviour of interspecific hybrids suggested the existence of 4 basic genomes of H, I, X and Y in the genus (Bachmann 1998). H. vulgare (2x) and H. bulbosum ( $2 x$, $4 x)$. have the I genome, $H$. marinum $(2 x, 4 x)$ and $H$. murinum $(2 x, 4 x, 6 x)$ have distinct genomes of $\mathrm{X}$ and $\mathrm{Y}$ respectively and the rest of diploid species have different forms of $\mathrm{H}$ genome.

Biochemical and molecular markers including storage protein fraction of barley (hordein), isoenzymes, RAPD and inter-simple sequence repeats (ISSR), amplified fragments length polymorphisms (AFLP) and chloroplast DNA have been used to study the species relationships in the genus Hordeum as well as revealing genetic diversity in these species (Jaaska 1994, Marillia and Scoles 1996, Nevo et al. 1997, Pakniyat et al. 1997, Badr et al. 2000, Echart-Almeida and CavalliMolina 2000, Kochieva et al. 2001, El-Rabey et al. 2002, Fernández et al. 2005, Hou et al. 2005, Sabine and Blattner 2006, Castillo et al. 2008).

Hordeum species grow in the north, north-west and south-west of Iran and are considered as important forage plants of the country. Parsa (1950), Mobayyen (1981) and Bor (1970) reported the occurrence of 11 Hordeum species in Iran; however the species recognition is varied by these authors. Our previous cytogenetic study of the genus contained karyotype analysis of some species (Sheidai and Rashid 2007), while the present study considers chiasma frequency and chromosome pairing in 6 populations of 4 species as well as RAPD analysis of 10 species of Iran.

Materials and methods

\section{Plant materials}

Hordeum species studied are 1-H. violaceum Boiss., 2-H. bogdanii Wilensky, 3-H. brevisubulatum Link., from the sect. Stenostachys Nevski, 4-H. marinum subsp. marinum Hudson, 5-H. glaucum Steud., 6-H. leporinum Link., from the sect. Hordeastrum Döll., 7-H. bulbosum L., from the sect. Bulbohordeum Nevski, 8-H. spontaneum C. Koch, 9-H. distichon L., and 10-H. vulgare L., from the sect. Crithe Düll. Voucher specimens are deposited in Herbarium of Shahid Beheshti University (HSBU). The names of localities (populations) have been given in caption of Fig. 1. 


\section{Cytological study}

Meiotic studies were performed on 6 populations of 4 species of $H$. bulbosum, $H$. distichon, $H$. spontaneum (3 populations) and H. leporinum. Young flower buds were collected from 10 randomly selected plants of each species/population and fixed in glacial acetic acid: ethanol $(1: 3)$ for $24 \mathrm{~h}$. Flower buds were washed and preserved in $70 \%$ ethanol at $4{ }^{\circ} \mathrm{C}$ until used (Sheidai et al. 2008). Cytological preparations used squash technique and 2\% aceto-orcein. Fifty to 100 pollen mother cells (PMCs) were analyzed for chiasma frequency and distribution at diakinesis and metaphase, and 500 PMCs were analysed for chromosome segregation during the anaphase I and telophase I.

For grouping of the species a combined data set was produced from meiotic data obtained in this study and karyotype data reported before (Sheidai and Rashid 2007). Since the species studied differed in their chromosome number, relative cytological data were used, for this purpose, mean of ring and rod bivalents per cell, mean of univalents per cell and total chiasmata per bivalent were used (Sheidai et al. 2008). Similarly karyotype features not affected by the chromosome number, including size of the longest and shortest chromosomes, total form percentage (TF\%) and A1 and A2 karyotype indices of Romero-Zarco (Sheidai and Rashid 2007) were used. Cluster analysis using Unweighted Paired Group with Arithmetic Average (UPGMA) and Neighbor Joining (NJ) methods was performed on relative cytological characteristics.

\section{DNA extraction and RAPD analysis}

DNA was extracted from leaves collected randomly from fresh plants or the herbarium specimens by use of NucleoSpin Plant kit (Macherey-Nagel, Germany). The PCR reaction mixture

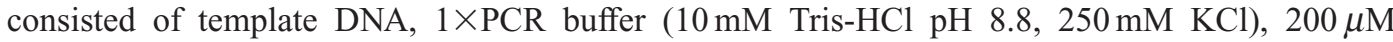
dNTPs, $0.80 \mu \mathrm{M} 10$-base random primers and 1 unit of Taq DNA polymerase, in a total volume of $25 \mu$ l. DNA amplification was performed on a palm cycler GP-001 (Corbet, Australia). Template DNA was initially denatured at $92^{\circ} \mathrm{C}$ for $3 \mathrm{~min}$, followed by 35 cycles of PCR amplification under the following parameters: denaturation for $1 \mathrm{~min}$ at $92^{\circ} \mathrm{C}$, primer annealing for $1 \mathrm{~min}$ at $36^{\circ} \mathrm{C}$ and primer extension for $2 \mathrm{~min}$ at $72^{\circ} \mathrm{C}$. A final incubation for $10 \mathrm{~min}$ at $72^{\circ} \mathrm{C}$ was performed. The PCR amplified products were separated by electrophoresis on a $\%$ agarose gels using $0.5 \times \mathrm{TBE}$ buffer (44.5 mM Tris/borate, $0.5 \mathrm{mM}$ EDTA, $\mathrm{pH}=8$ ) or $12 \%$ polyacrylamide gels. The gels were stained with ethidium bromide and visualized under UV light or silver stained for added sensitivity. RAPD markers were named by primer origin, followed with the primer number and the size of amplified products in base pairs.

Twenty random primers supplied by Operon technology (Alameda, California) were used. In molecular analysis, only unambiguous and stable PCR fragments that consistently appeared in 2 replications were scored as binary characters and coded accordingly (presence $=1$, absence $=0$ ). Grouping of the species was performed by using different clustering methods based on Dice and Jaccard similarity indices determined among the species studied (Ingrouille 1986, Podani 2000). The fit of dendrograms obtained by different clustering methods was checked by cophenetic correlation (Ingrouille 1986, Podani 2000). NTSYS ver. 2.1 (1998) was used for statistical analyses.

\section{Results and discussion}

\section{RAPD analysis}

Out of 20 RAPD primers used 11 produced 18 reproducible polymorphic bands (Fig. 1). Specific bands were observed in some of the species or populations for example band B05-1 occurred only in H. brevisbulatum and populations of $H$. glaucum, while band R12-1 was present only in H. bogdanii and band R12-3 occurred only in the Khoozestan population of H. marinum.

Some bands occurred in all the species except 1, for example bands B05-3 and B05-4 was present in all except $H$. brevisbulatum, RAPD band A11-1 was present in all except in $H$. 
brevisbulatum and $H$. violaceum, while band A11-4 was absent only in $H$. brevisbulatum, the Evin population of $H$. leporinum and $H$. violaceum.

Two clustering methods performed on RAPD data produced similar results and since the NJ dendrogram showed the highest cophenetic correlation $(r>0.86)$ (Fig. 2). The Dendrogram obtained showed separation of $H$. vulgare and $H$. spontaneum although these species show more affinity compared to the other species studied. Taxonomists variously consider $H$. vulgare ssp. vulgare and $H$. vulgare ssp. spontaneum as 2 subspecies or as species. $H$. spontaneum has been identified either as an ancestral form or as a feral form of cultivated barley; however many believes that $H$. vulgare is descended from wild barley H. spontaneum (Badr et al. 2000, Young 2001). A study of RAPD analysis by Kochieva et al. (2001) also revealed high similarity between $H$. vulgare and $H$. spontaneum and considered them as 2 subspecies that are well differentiated.

$H$. spontaneum is an annual plant with diploid and self-pollinating. The genetic diversity of $H$. spontaneum has been identified by isozyme polymorphisms (Liu et al. 2002) RFLP markers (Zhang et al. 1993), SSR-markers (Matus and Hayes 2000), AFLP markers (Pakniyat et al. 1997) and SNPmarkers (Kanazin et al. 2002). H. spontaneum shows more variation than cultivated barley, and many alleles are associated with specific environments and distinct geographic patterns of genetic diversity are maintained in wild barley (H. spontaneum) despite migration (Morrell et al. 2003). Separation of $H$. spontaneum and $H$. vulgare populations in different clusters obtained in the present study also supports such inter-population variations.

In recent taxonomic treatments of the sea barley (H. marinum S.L.), 2 entities have been recognized namely $H$. marinum and $H$. geniculatum, either at the species level or at the sub-specific level (Sahebi et al. 2004). Based on gross morphology, the 2 entities differ by the shape of the glumes of the lateral spikelets, being heteromorphous in $H$. marinum and homomorphous in $H$. geniculatum, i.e., the lower glume is wide-winged in the former and without such a wing in the latter. In the present study only H. marinum subsp. marinum could be collected and included for RAPD analysis.

Three species of $H$. marinum subsp. marinum, $H$. glaucum and $H$. leporinum from the sect. Hordeastrum are grouped together, $H$. marinum and $H$. leporinum are placed close to each other in a single cluster, while $H$. glaucum joins them with some distance. RFLP of chloroplast DNA also separated H. glaucum from H. leporinum and H. murinum (Baum and Bailey 1989). In other studies, RAPD analysis (De Bustose et al. 1998) also showed close affinity of $H$. marinum and $H$. leporinum while AFLP analysis (El-Rabey et al. 2002) showed close affinity of H. glaucum and $H$. leporinum.

Three species of $H$. violaceum, $H$. bogdanii and $H$. brevisubulatum, from the sect. Stenostachys with the $\mathrm{H}$ genome are placed in different clusters separated from each other. Therefore RAPD data is not congruent with morphological characters grouping of these species. This result may support Bothmer et al. (1995) suggestion that cytogenetic and biochemical data produce different evolutionary hierarchies compared to that of morphological characters in the Hordeum. Fernández et al. (2005) also agree with Bothmer et al. (1995) suggestion; they studied biochemical variation to determine phylogenetic relationships between Hordeum chilense and other American species of the Hordeum using slab gel electrophoresis techniques and concluded that: 1) Conventional classification based on morphological characters does not totally agree with biochemical data, 2) Sect. Anisolepis and Critesion seem to be clearly differentiated, 3) The accessions classified as $H$. compressum present biochemical phenotypes quite different from the rest of the species, 4) $H$. stenostachys, $H$. muticum and $H$. chilense constitute a group of variable species with many biochemical similarities and close phylogenetic relationships and 5) The evolutionary pattern of these American species seems to follow a model of reticulate evolution. 

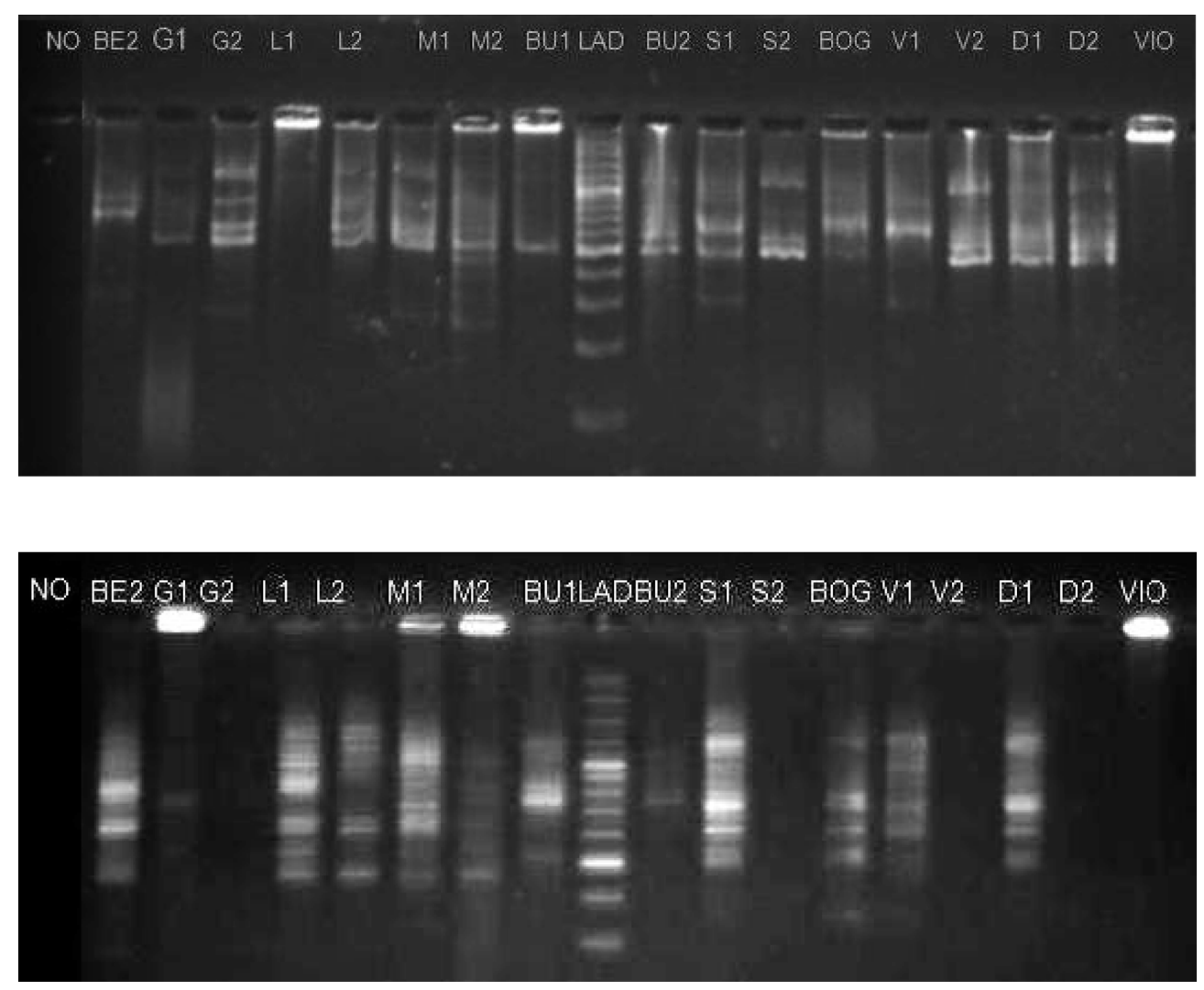

Fig. 1. RAPD profile of primers OPA11 (top) and OPR02 (bottom) in Hordeum species studied. Abbreviations: $\mathrm{NO}=$ No DNA, BE1=Lorestan population of $H$. brevisubulatum, $\mathrm{G} 1, \mathrm{G} 2=$ Tehran and Isfahan populations of $H$. glaucum, L1, L2=Tehran and Mazandaran populations of $H$. leporinum, M1, M2=Khoozestan and Gilan populations of $H$. marinum subsp. marinum, $\mathrm{BU} 1=$ Tehran population of $H$. bulbosum, $\mathrm{LAD}=$ Molecular ladder, BU2 = Lorestan population of H. bulbosum, S1, S2=Shiraz and Golestan populations of $H$. spontaneum, BOG=Kerman population of $H$. bogdanii, V1, V2=Isfahan and Mazandaran populations of $H$. vulgare, D1, $\mathrm{D} 2=$ Tehran and Khoozestan populations of $H$. distichon and $\mathrm{VIO}=\mathrm{Gilan}$ population of $H$. violaceum.

\section{Cytology}

The chromosome number and meiotic details of the Hordeum species and populations studied are presented in Table 1 and Fig. 3. The Tehran population of $H$. bulbosum possessed $2 n=4 x=28$ supporting the earlier reports (Strid and Franzen 1981, Semenov 1986). Bothmer (1979) reported $2 n=28$ and $2 n=42$ for H. bulbosum. Previously Sheidai and Rashid (2007) based on karyotype study reported $2 n=2 x=14$ for Tehran population of $H$. bulbosum, while the present meiotic study of the same population shows the presence of tetraploid indicating the occurrence of 2 polyploidy level for this species in Iran.

The Darabad population of $H$. distichon possessed $2 n=2 x=14$ chromosome number, supporting earlier reports (Zhang et al. 1990, Sheidai and Rashid 2007). The Evin population of $H$. leporinum possessed $2 n=6 x=42$ chromosome number. The earlier studies reported diploid and tetraploid chromosome numbers for this species (Hatch 1980, Valdés et al. 1999), while recently Sheidai and Rashid (2007) reported hexaploid for this species based on karyotype study of the Shahzand population in Iran which is supported by present meiotic analysis. Three populations of H. spontaneum studied showed $2 n=2 x=14$ supporting earlier reports (Kahler et al. 1981, Jahan et 


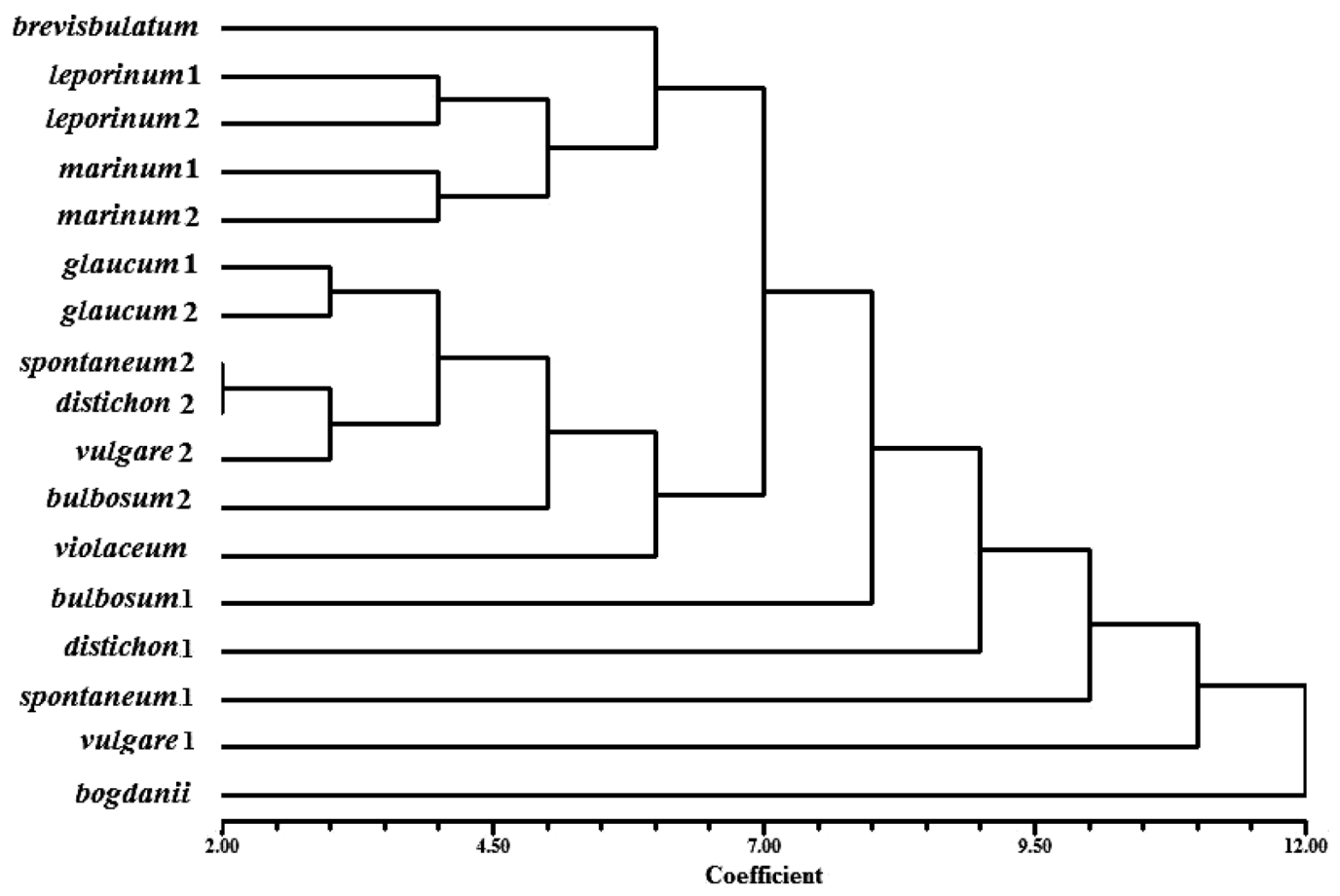

Fig. 2. NJ dendrogram of Hordeum species based on RAPD data. Species localities as in Fig. 1.

al. 1992, Sheidai and Rashid 2007).

Meiotic analysis of Hordeum species and populations studied showed that the chromosomes mainly formed bivalents at metaphase I (Figs. 3A-D). Chromosomes segregation during anaphase was normal in most of the anaphase and telophase cells in all the species studied, except in a few cases of laggard chromosomes formation and chromosome stickiness observed in $H$. bulbosum (Figs. 3E, F). Laggard chromosomes led to formation of micronuclei in this species (Figs. 3G).

The Darake population of $H$. bulbosum and $H$. leporinum showed 0-2 B-chromosomes which were smaller than A-chromosomes and did not pair with them (Fig. 3H, I). The B-chromosomes (Bs) show numerical polymorphism and when present in high number affect negatively the growth and vigor of the plants, while in low number may benefit the plant possessing them. Since few meiocytes having B chromosomes were obtained in this study we could not analyse the effects of Bs on chiasma frequency and distribution which will be done in future detailed study of Bs in Hordeum species and populations. To our knowledge this is the first report on the occurrence of B chromosome in Hordeum species.

Bao-Rong (1997) studied chromosome pairing and chiasma frequency in parental species and hybrids of $H$. bulbosum, $H$. bogdanii, $H$. vulgare, H. stenostachys and $H$. murinum which all formed mainly bivalents in metaphase of meiosis-I with few cases of univalents. The values obtained for chromosome associations and chiasma frequency were in close range to the values of Hordeum species studied by us.

Grouping of the Hordeum species by different clustering methods based on relative cytological data (Table 1) produced similar results (Fig. 4) and since the UPGMA dendrogram showed the highest cophenetic correlation (0.84) it is discussed here.

Two species of $H$. bulbosum and $H$. vulgare are separated from each other but do not show 


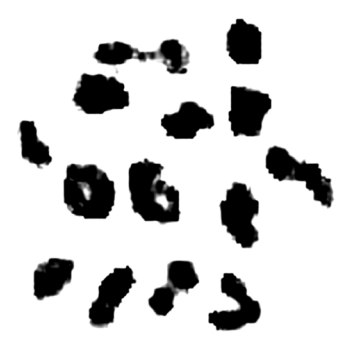

A

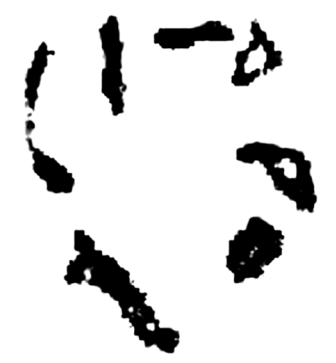

D

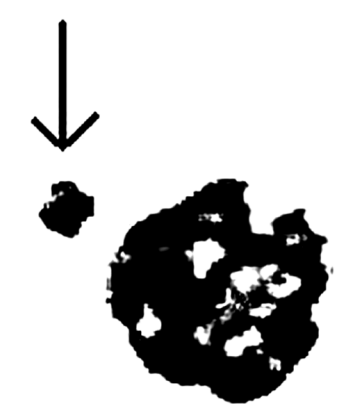

G

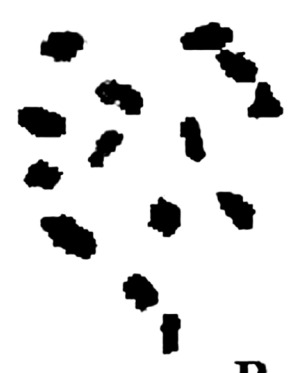

B

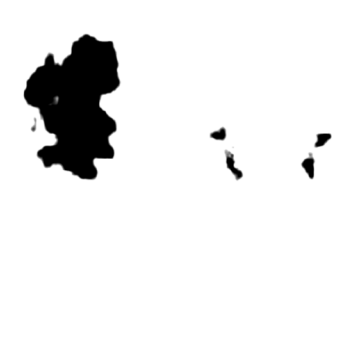

E

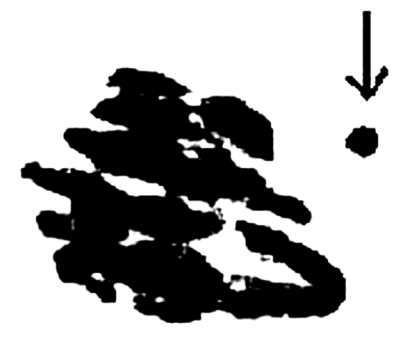

H

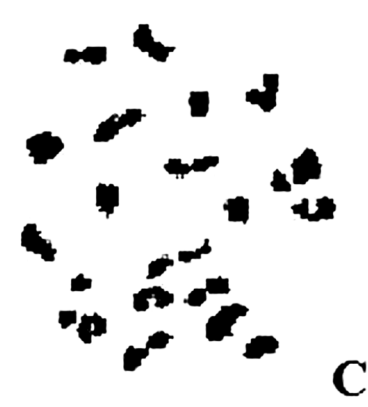

C 
Table 1. Relative meiotic characters and karyotype features in Hordeum species studied

\begin{tabular}{llllllllllll}
\hline \hline & $2 n$ & RBN & RDN & IN & TXN & L & S & TF & A1 & A2 \\
\hline H. bogdanii & 14 & 0.93 & 0.05 & 0.02 & 1.95 & - & - & - & - & - \\
H. vulgare & 14 & 0.97 & 0 & 0 & 1.97 & 31.7 & 14.55 & 38.86 & 0.36 & 25.96 \\
H. spontaneum & 14 & 0.75 & 0.25 & 0 & 1.75 & 19.33 & 12.49 & 41.97 & 0.27 & 16.54 \\
H. bulbosum & 28 & 0.41 & 0.38 & 0 & 1.91 & 20.5 & 13.75 & 41.9 & 0.26 & 16.49 \\
H. leporinum & 42 & 0.80 & 0.18 & 0 & 1.8 & 23.25 & 11 & 40.11 & 0.3 & 22.97 \\
H. distichon & 14 & 0.73 & 0.32 & 0 & 1.77 & 22.87 & 14.49 & 40.34 & 0.29 & 16.75 \\
H. glaucum & 14 & - & - & - & - & 20.25 & 12 & 40.2 & 0.31 & 16.49 \\
H. marinum & 14 & - & - & - & - & 19.18 & 10.25 & 38.25 & 0.36 & 20.64 \\
\hline
\end{tabular}

$\mathrm{RBN}=$ Ring bivalent per cell, $\mathrm{RDN}=$ Rod bivalent per cell, $\mathrm{IN}=$ Univalent bivalent per cell, $\mathrm{TXN}=$ Total chiasmata per chromosome, $\mathrm{L}=$ Size of the longest chromosome $(\mu \mathrm{m}), \mathrm{S}=$ Size of the shortest chromosome $(\mu \mathrm{m}), \mathrm{TF}=$ Total form percentage, $\mathrm{A} 1=$ Intra-chromosomal index, A2 = Inter-chromosomal index.

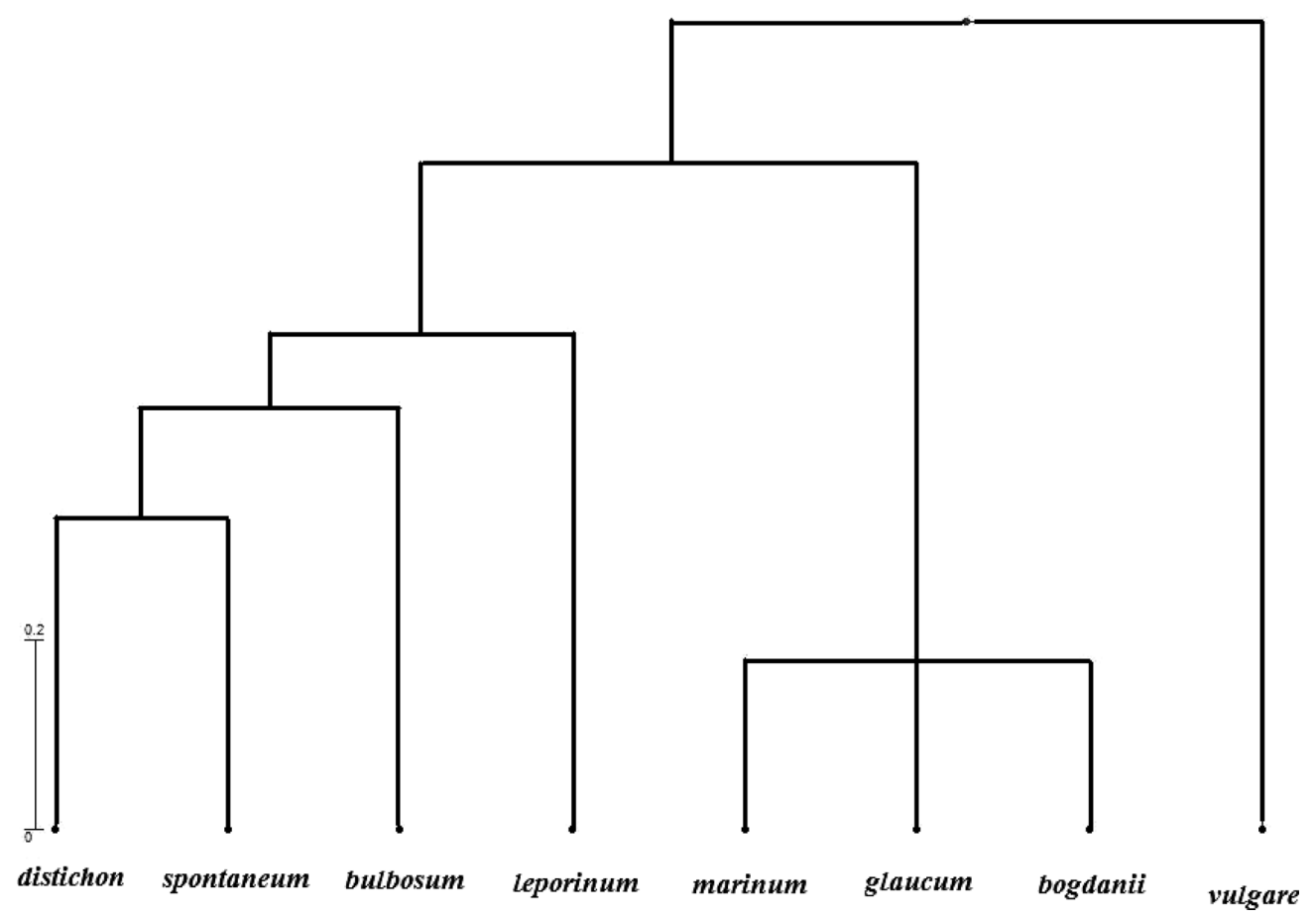

Fig. 4. UPGMA clustering of Hordeum species based on relative cytological data.

more similarity in contrast with RAPD analysis explained before. The species of $H$. marinum subsp. marinum has $\mathrm{X}$ genome, while H. glaucum and H. leporinum contains $\mathrm{H}$ genome. In general it seems that cytological data used also show gross affinity of the Hordeum species studied which is almost in general agreement with RAPD data obtained.

\section{References}

Åberg, E. 1940. The taxonomy and phylogeny of Hordeum L. sec. Seralia Ands., with special reference to Tibetan barleys. Symb. Bot. Upsal. 4: 1-156.

Bachmann, K. 1998. Species as units of diversity: an outdated concept. Theor. Biosci. 117: 213-230. 
Badr, A., Muller, K., Schafer-Pregl, R., Rabey, H., Effgen, S., Ibrahim, H. H., Pozzi, C. and Bao-Rong, L. 2000. A study on systematic relationships between Elymus and Hordeum (Poaceae). Acta Phytotax. Sinica 35: 193-207.

Bao-Kong 1997 (p 2)

Baum, B. R. and Bailey, L. G. 1989. Species relationships in the Hordeum murinum aggregate viewed from chloroplast DNA restriction fragment patterns. Theor. Appl. Genet. 78: 311-317.

Blattner, F. R. 2004. Phylogenetic analysis of Hordeum (Poaceae) as inferred by nuclear rDNA ITS sequences. Mol. Phylogenet. Evol. 33: 289-299.

Bor, N. L. 1970. Hordeum. In: Reschinger, K. H. (ed.). Flora Iranica No. 70: 232-244. Akademische Druck. Verlagsanstalt, Graz.

Bothmer, R. V. 1979. Revision of the Asiatic taxa of Hordeum sect. Stenostachys. Botanisk Tidsskrift 74: 117-146.

— and Jacobsen, N. 1985. Origin, taxonomy and related species. In Rasmussun D. (ed.), Barley Monographs, ASA 26: 19-56.

—, Flink, J. and Landstrom, T. 1986a. Meiosis in interspecific Hordeum hybrids. I. Diploid combinations. Can. J. Genet. Cytol. 28: 525-535.

- - - and Linde-Laursen, I. 1986b. Development and meiosis of three interspecific hybrids with cultivated barley $(H$. vulgare L.). Z Pflanzenzuchtg 96: 107-114.

- - - and Landstrom, T. 1987. Meiosis in Hordeum interspecific hybrids. II. Triploid hybrids. Evol. Trend. Plant. 1: 41-50.

—, Jacobsen, N., Baden, C., Jorgensen, R. B. and Linde-Laursen, I. 1991. An ecogeographical study of the genus Hordeum. IBPGR, Rome.

- - - - - - - and —. 1995. An ecogeographical study of the genus Hordeum. 2nd ed. IBPGR, Rome.

Castillo, A., Budak, H., Varshney, R. K., Dorado, G., Graner, A. and Hernandez, P. 2008. Transferability and polymorphism of barley EST-SSR markers used for phylogenetic analysis in Hordeum chilense. BMC Plant Biol. 8: 97-106.

De Bustose, A., Casanova, C., Soler, C. and Jouve, N. 1998. Ecological correlates of RAPD DNA diversity of wild barley, Hordeum spontaneum, in the Fertile Crescent. Genet. Resour. Crop. Evol. 45: 151-159.

Echart-Almeida, C. and Cavalli-Molina, S. 2000. Hordein variation in Brazilian barley varieties (Hordeum vulgare L.) and wild barley (H. euclaston Steud. and H. stenostachys Godr.). Genet. Mol. Biol. 23: 425-433.

El-Rabey, H. A., Badr, A., Schäfer-Pregl, R., Martin, W. and Salamini, F. 2002. Speciation and species separation in Hordeum L. (Poaceae) resolved by discontinuous molecular markers. Plant. Biol. 4: 567-575.

Fernández, J. A., Sanz, J. and Jouve, N. 2005. Biochemical variation to determine phylogenetic relationships between Hordeum chilense and other American species of the genus Hordeum (Poaceae). Plant. Syst. Evol. 157: 105-119.

Hatch, S. L. 1980. Chromosome numbers of some grasses from the southwestern United States and Mexico. The Southwestern Naturalist 25: 278-280.

Hou, Y. C., Yan, Z. H., Wei, Y. M. and Zheng, Y. L. 2005. Genetic diversity in barley from west China based on RAPD and ISSR analysis. Barley Geneti. Newslett. 35: 9-22.

Ingrouille, M. J. 1986. The construction of cluster webs in numerical taxonomic investigations. Taxon 35: 541-545.

Jaaska, V. 1994. Isoenzyme evidence on the systematics of Hordeum section Marina (Poaceae). Plant. Syst. Evol. 191: 213-226.

Jahan, B., Vahidy, A. A. and Ali, S. I. 1992. Chiasma frequency and chromosome associations in sixteen taxa of Hordeum species. Cytologia 57: 51-57.

Kanazin, V., Talbert, H., See, D., De Camp, P., Nevo, E. and Blake, T. 2002. Discovery and assay of single nucleotide polymorphisms in barley (Hordeum vulgare L.). Plant Mol. Biol. 48: 529-537.

Kahler, A. L., Moris, M. I. and Allard, R. W. 1981. Gene triplication and fixed heterozygosity in diploid wild barley. J. Heredity 72: 374-376.

Kochieva, E. Z., Goryunova, S. V. and Pomortsev, A. A. 2001. RAPD Analysis of the Genome in species of the Genus Hordeum. Russian. J. Genet. 37: 905-910.

Liu, F., Sun, G. L., Salomon, B. and Bothmer, V. R. 2002. Characterization of genetic diversity in core collection accessions of wild barley, Hordeum vulgare spontaneum. Hereditas 136: 67-73.

Marillia, E. F. and Scoles, G. J. 1996. The use of RAPD markers in Hordeum phylogeny. Genome 39: 646-654.

Matus, I. A. and Hayes, P. M. 2000. Genetic diversity in three groups of barley germplasm assessed by simple sequence repeats. Genome 45: 1095-1106.

Mobayyen, S. 1981. Seedlings of Iran and Flora of Vascular Plants. Vol. 1. Tehran University Publication, Tehran.

Morrell, P. L., Lundy, K. E. and Clegg, M. T. 2003. Distinct geographic patterns of genetic diversity are maintained in wild barley (Hordeum vulgare ssp. spontaneum) despite migration. Proc. Nat. Acad. Sci. USA. 100: 10812-10817.

Nevo, E., Baum, B., Beiles, A. and Johnson, D. A. 1997. Ecological correlates of RAPD DNA diversity of wild barley, Hordeum spontaneum, in the Fertile Crescent. Biologia Plantarum 39: 543-552.

Nevski, S. A. 1941. Beiträge zur Kenntnis der Wildwachsenden Gersten in Zusammenhang mit der Frage des Ursprungs von Hordeum vulgare L. und Hordeum distichon L. (Versuch einer Monographie der Gattung Hordeum). Trudy. Bot. 
Inst. Akad. Nauk. SSSR. Ser. 1. 5: 64-255.

Parsa, A. 1950. Flora de L', Iran. Vol. 4. Publications du Ministére de L' education. Mseun d' historic naturelle de Tehran.

Pakniyat, H., Powell, W., Baird, E., Handley, L. L., Robinson, D., Scrimgeour, C. M., Nevo, E., Hackett, C. A., Caligari, P. D. S. and Forster, B. P. 1997. AFLP variation in wild barley (Hordeum spontaneum C. Koch) with reference to salt tolerance and associated ecogeography. Genome 40: 332-341.

Petersen, G. and Seberg, O. 1997. Phylogenetic analysis of the Triticeae (Poaceae) based on rpoA sequence data. Mol. Phylogenet. Evol. 7: 217-30.

Podani, J. 2000. Introduction to exploration of multivariate biological data. English Translation, Backhuys Publishers, Leiden, pp. 407.

Sabine, S. J. and Blattner, F. R. 2006. A Chloroplast Genealogy of Hordeum (Poaceae): Long-Term Persisting Haplotypes, Incomplete Lineage Sorting, Regional Extinction, and the Consequences for Phylogenetic Inference. Mol. Biol. Evol. 23: 1602-1612.

Sahebi, J., Rahiminejad, M. R. and Ghahreman, A. 2004. A taxonomic review of the Hordeum marinum senso lato (Poaceae: Triticeae) in Iran. Iran J. Sci. Tech. Trans. A. 28: 127-135.

Seberg, O. and Frederiksen, S. 2001. A phylogenetic analysis of the monogenomic Triticeae (Poaceae) based on morphology. Bot. J. Linn. Soc. 136: 75-97.

Semenov, V. I. 1986. Vnutrikhromosomnaja topografija geterokhromatina u zlakovykh. Bjull. Glavnogo. Botanic. Sada. 140: $68-73$

Sheidai, M. and Rashid, S. 2007. Cytogenetic study of some Hordeum L. species in Iran. Acta. Biol. Zseged. 51: $107-112$.

- Parsian, H., Vaezi-Joze, S. and Noormohammadi, Z. 2008. Chromosome pairing and chiasma formation in some olive (Olea europaea L.) cultivars of Iran. Cytologia 73: 269-274.

Shewry, P. R. 1992. Barley: Genetics, Biochemistry, Molecular Biology and Biotechnology. CAB International Oxford.

Strid, A. and Franzen, R. 1981. In Chromosome number reports LXXIII. Taxon 30: 829-842.

Valdés, B., Parra, R., Sánchez, A. M. and Díaz, M. D. 1999. Números cromosómicos de plantas de Marruecos, IV. Lagascalia 21: 235-240.

Watson, L., and Dallwitz, M. J. 1992 onwards. The grass genera of the world: descriptions, illustrations, identification, and information retrieval; including synonyms, morphology, anatomy, physiology, phytochemistry, cytology, classification, pathogens, world and local distribution, and references. Version: 28th November 2005. http://deltaintkey.com.

Young, B. 2001. Barley; The Versatile Crop. South Illinois University, College of Science, Ethnobotanical Leaflets.

Zhang, Q., Maroof, M. A. S. and Kleinhofs, A. 1993. Comparative diversity analysis of RFLPs and isozymes within and among populations of Hordeum vulgare spontaneum. Genetics 134: 909-916.

Zhang, Z. P., Zhang, Y. M., and Yuan, J. Z. 1990. A study of the chromosomes of Triticum aestivum and Hordeum distichon by silver staining. Acta. Agric. Univ. Henan 24: 82-85. 